\title{
INCREASED TEMPERATURE IN URBAN GROUND AS SOURCE OF SUSTAINABLE ENERGY
}

\author{
J. RIVERA ${ }^{1}$, S. BENZ ${ }^{2}$, P. BLUM ${ }^{2} \&$ P. BAYER ${ }^{1}$ \\ ${ }^{1}$ ETH Zurich, Department of Earth Sciences, Switzerland \\ ${ }^{2}$ Karlsruhe Institute of Technology (KIT), Institute for Applied Geosciences (AGW), Germany
}

\begin{abstract}
Densely urbanized areas are characterized by special microclimatic conditions with typically elevated temperatures in comparison with the rural surrounding. This phenomenon is known as the urban heat island (UHI) effect, but not restricted exclusively to the atmosphere. We also find significant warming of the urban subsurface and shallow groundwater bodies. Here, main sources of heat are elevated ground surface temperatures, direct thermal exploitation of aquifers and heat losses from buildings and other infrastructure. By measuring the shallow groundwater temperature in several European cities, we identify that heat sources and associated transport processes interact at multiple spatial and temporal scales. The intensity of a subsurface UHI can reach the values of above $4 \mathrm{~K}$ in city centres with hotspots featuring temperatures up to $+20^{\circ} \mathrm{C}$. In comparison with atmospheric UHIs, subsurface UHIs represent long-term accumulations of heat in a relatively sluggish environment. This potentially impairs urban groundwater quality and permanently influences subsurface ecosystems. From another point of view, however, these thermal anomalies can also be seen as hidden large-scale batteries that constitute a source of shallow geothermal energy. Based on our measurements, data surveys and estimated physical ground properties, it is possible to estimate the theoretical geothermal potential of the urban groundwater bodies beneath the studied cities. For instance, by decreasing the elevated temperature of the shallow aquifer in Cologne, Germany, by only $2 \mathrm{~K}$, the obtained energy could supply the space-heating demand of the entire city for at least 2.5 years. In the city of Karlsruhe, it is estimated that about $30 \%$ of annual heating demand could be sustainably supplied by tapping the anthropogenic heat loss in the urban aquifer. These results reveal the attractive potential of heated urban ground as energy reservoir and storage, which is in place at many places worldwide but so far not integrated in any city energy plans.
\end{abstract}

Keywords: energy waste, shallow geothermal energy, sustainability, urban aquifers.

\section{INTRODUCTION}

Increased temperatures beneath cities have been reported in several studies in northern countries. Local surveys in North America (e.g., Ferguson and Woodbury [1], Taylor and Stefan [2], Eggleston and McCoy [3]), Europe (e.g., Balke [4], Menberg et al. [5], Müller et al. [6], García-Gil et al. [7], Epting and Huggenberger [8]), and Asia (e.g., Taniguchi et al. [9], Yamano [10], Liu et al. [11], Zhan et al. [12]) have shown regional thermal anomalies of around $2-5 \mathrm{~K}$ in comparison to the undisturbed surrounding. In these subsurface urban heat islands (SUHIs), heat from anthropogenic sources propagates into the urban subsurface increasing the temperature and changing the thermal conditions in shallow ground and groundwater (Fig. 1). The regionally increased temperature is also called SUHI intensity. 


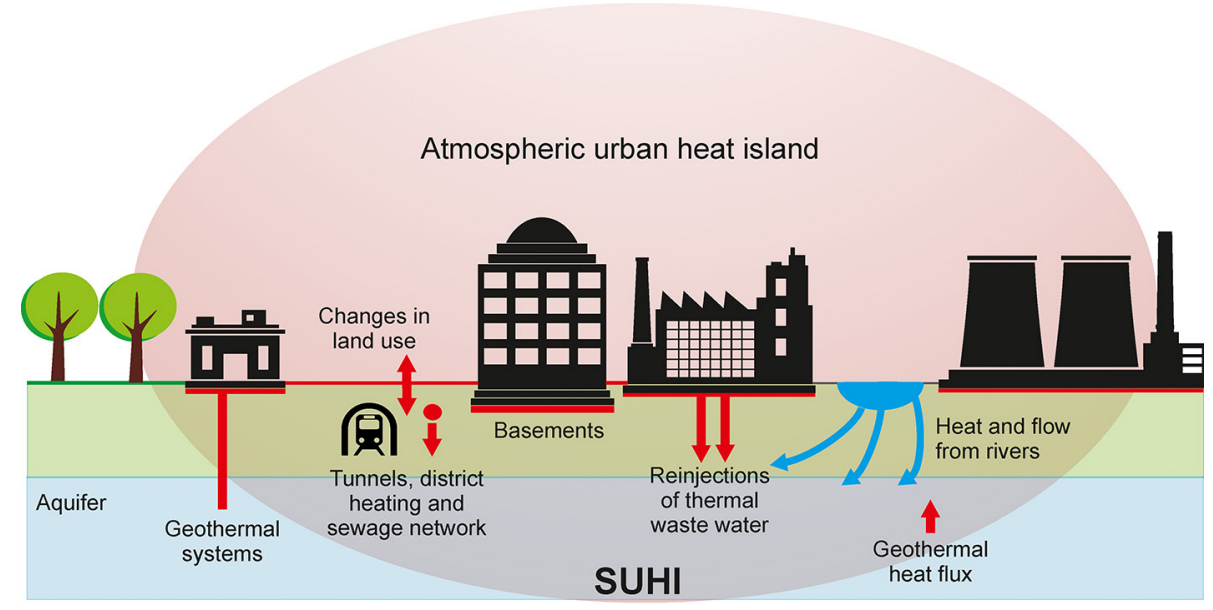

Figure 1: Representation of interacting processes within a subsurface urban heat island (SUHI).

In Europe, one of the first comprehensive studies was presented by Balke [4], who investigated the temperature regime in the shallow aquifer of Cologne, Germany. This was done by temperature measurements in multiple groundwater wells in the city. By constructing contour plots at $20 \mathrm{~m}$ depth, a SUHI reaching an intensity of $5 \mathrm{~K}$ was resolved beneath the city centre. In similar detail, Hötzl and Makurat [13] investigated the shallow thermal conditions beneath the city of Karlsruhe in 1981. It was shown that the SUHI intensity beneath the city centre reached at least $3 \mathrm{~K}$, and that horizontal groundwater flow promotes the downstream transport of heat.

While more recent studies focused on the environmental impact of SUHIs (e.g Müller et al. [6], Bonte et al. [14], Brielmann et al. [15]), others have studied their associated geothermal potential (e.g., Allen et al. [16], Arola and Korkka-Niemi [17], Sinnathamby et al. [18]). Zhu et al. [19], Zhang et al. [20] for instance evaluated this potential in several cities including London, Prague, Cologne, Winnipeg and Beijing. The results indicate that by using geothermal systems for decreasing the SUHI intensity, the amount of energy extracted is several times higher than the annual heating demand in these cities. Additionally, the elevated temperatures are crucial for adjusting and enforcing environmental regulations (Hähnlein et al. [21], Vienken et al. [22]), and they are relevant for technological issues related to conventional shallow geothermal systems (e.g., Banks [23], Rybach and Eugster [24]).

Extracting this shallow geothermal potential requires a comprehensive underground management of the energy content since an unbalanced exploitation scheme progressively degrades the low-enthalpy energy resources (e.g., Rivera et al. [25]). Possible ways around are implementation of centralized district heating and/or cooling networks for distributing locally unbalanced energy loads (e.g. Arola and Korkka-Niemi [17], Zhang et al. [20]) or direct heat sources. In such "smart energy" management, the urban underground can be conceived as a reservoir that buffers the spatial and seasonal variability of the energy demand.

This work presents a description of the spatial distribution of SUHIs in several German cities including Cologne, Berlin, Munich and Karlsruhe. Finally, the 
associated energy content is estimated and compared with case-specific space-heating demands.

\section{MATERIALS AND METHODS}

\subsection{Study cases and available data}

The spatial distribution of shallow groundwater temperatures (GWT) was estimated in four German cities. The study cases (Table 1) cover a wide range of population densities with specific patterns in the subsurface thermal alteration. The measured surface air temperatures (SAT) reflect a moderate climate, and the dominant sedimentary deposits are likely sensitive to intensified downward heat fluxes.

The spatial distribution of GWT is obtained from a fairly large number of observation wells that the respective municipalities use for monitoring groundwater quality among other parameters. The wells are not only located within the urban areas but also in the suburban surroundings, which is fundamental in estimating the relative intensity of the subsurface urban heat islands.

In Berlin, these measurements were carried out by the Senate Department for Urban Development and the Environment in 2010 at $0 \mathrm{~m}$ above sea level (asl), corresponding to a depth of about 30-60 m below ground level [26]. In Munich, a measurement campaign was conducted in 1983 on a dense network of observation wells along the subway system [27]. In Karlsruhe in turn, the shallow GWT is daily recorded by the Public Works Service through data loggers installed at depths of about 9-12 m. Due to the typical seasonal variability of the temperature data at these depths, the arithmetic annual mean for the year 2012 is used for the present analysis. Finally in Cologne, this study uses the data from Zhu et al. [19] that describes the spatial distribution of groundwater temperature in 2009. In all cases, the spatially distributed temperatures are visualized and interpolated via kriging in GIS (ESRI $\left.{ }^{\circledR} \operatorname{ArcInfo}^{\mathrm{TM}} 10.0\right)$.

Table1: Characteristics of the studied German cities. The annual mean air temperature values are given for the time period 1961-1990.

\begin{tabular}{|c|c|c|c|c|}
\hline Parameter & Berlin & Munich & Cologne & Karlsruhe \\
\hline Mean altitude (masl) $)^{(a)}$ & 75 & 518 & 53 & 115 \\
\hline Population (pop.) ${ }^{(\mathrm{a})}$ & 3'421'829 & $1^{\prime} 407^{\prime} 836$ & 1'036'253 & $299^{\prime} 103$ \\
\hline Pop. density (pop./km²) (a) $^{(a)}$ & 3838 & 4531 & 2557 & 1724 \\
\hline Total area $\left(\mathrm{km}^{2}\right)^{(\mathrm{a})}$ & 892 & 311 & 405 & 173 \\
\hline Annual mean SAT $\left({ }^{\circ} \mathrm{C}\right)^{(\mathrm{b})}$ & 8.9 & 9.2 & 10 & 10.7 \\
\hline Shallow aquifer material & $\begin{array}{l}\text { Gravel, sand, } \\
\text { silt, clay, till }\end{array}$ & Gravel, sand ${ }^{(\mathrm{d})}$ & Gravel, sand ${ }^{(\mathrm{e})}$ & Sand, gravel ${ }^{(\mathrm{f})}$ \\
\hline $\begin{array}{l}\text { Measurement depth } \\
(\mathrm{m} . \text { b.g.l })^{(\mathrm{g})}\end{array}$ & 20 & $2-20$ & 15 & $9-12$ \\
\hline Observation wells ${ }^{(\mathrm{g})}$ & 123 & 492 & 52 & 82 \\
\hline
\end{tabular}

(a)Federal Statistical Office (2014); (b) German Weather Service (2014); (c) Hannappel and Limberg [28]; (d)Seiler [29], Zosseder [30]; (e)Zhu et al. [19]; ( ${ }^{(\mathrm{f})}$ Geyer and Gwinner [31]; (g) Menberg et al. [5]. 
Table 2: Hydrogeological and thermo-physical parameters of the studied cities.

\begin{tabular}{lccc}
\hline City & $\begin{array}{c}\text { Aquifer thickness [m] } \\
\min -\max (\operatorname{mean})\end{array}$ & $\begin{array}{c}\text { Porosity }[-]^{(\mathrm{e})} \\
\min -\max (\operatorname{mean})\end{array}$ & $\begin{array}{c}\text { Volumetric heat capacity of } \\
\text { solid }\left[\mathrm{MJ} \mathrm{m}^{-3} \mathrm{~K}^{-1}\right] \\
\min -\max (\mathrm{mean})\end{array}$ \\
\hline Berlin & $30-50(40)^{(\mathrm{a})}$ & $0.15-0.25(0.20)$ & $2.0-2.2(2.1)^{(\mathrm{f})}$ \\
Munich & $5-20(10)^{(\mathrm{b})}$ & $0.20-0.25(0.23)$ & $2.3-2.5(2.4)^{(\mathrm{f})}$ \\
Cologne & $10-30(20)^{(\mathrm{c})}$ & $0.15-0.25(0.20)$ & $2.1-2.2(2.2)^{(\mathrm{f})}$ \\
Karlsruhe & $10-50(30)^{(\mathrm{d})}$ & $0.15-0.25(0.20)$ & $2.2-2.6(2.4)^{(\mathrm{f})}$ \\
\hline
\end{tabular}

Hydrogeological data and values for porosity and thermal properties taken from: ${ }^{(a)}$ Limberg et al. and Thierbach [33]; ${ }^{(b)}$ Kerl et al. [34]; ${ }^{\left({ }^{c}\right)}$ Zhu et al. [19]; ${ }^{(d)}$ Schafer et al. [35]; ${ }^{\left({ }^{e}\right)}$ Prinz et al. And Strauss [36]; ${ }^{(f)}$ VDI [32].

\subsection{Geothermal potential of subsurface urban heat islands}

The volumetric heat capacity of the porous medium $C_{m}\left(\mathrm{~kJ} \mathrm{~m}^{-3} \mathrm{~K}^{-1}\right)$ can be used for estimating the energy yield due to a change of temperature $\Delta T(\mathrm{~K})$ in a given reference volume $V\left(\mathrm{~m}^{3}\right)$. This approach was followed by Zhu et al. [19] to quantify the theoretical geothermal potential in urban aquifers with elevated GWT. Provided that the thermo-physical and hydrogeological parameters of the aquifer are known, the heat content $Q(\mathrm{~kJ})$ can be calculated by:

$$
Q=C_{m} \Delta T V=\left[n C_{w}+(1-n) C_{s}\right] \Delta T V
$$

where $C_{m}$ is obtained assuming a fully saturated medium in which volumetric energy contributions from water $C_{w}$ and from solids $C_{s}$, are weighted according to the medium porosity $n$. This parameter and the aquifer thickness (required to calculate the volume $V$ ) are listed in Table 2 for the studied cities.

The parameters included in eqn. (1) considerably vary in space. In order to cope with this geological heterogeneity, parameter ranges and a respective mean value were defined based on hydrogeological data from literature (Table 2). For the heat capacity of water a fixed value of $4150 \mathrm{~kJ} \mathrm{~m}^{-3} \mathrm{~K}^{-1}$ was taken [32].

Following Zhu et al. [19], the temperature reduction is set to $\Delta T=2-6 \mathrm{~K}$, with a mean value of $\Delta T=4 \mathrm{~K}$ (oriented at SUHI intensity). The calculated energy content $Q$ is contrasted with the space-heating demand of the individual cities. The latter is estimated by the average living space and the average annual unit heating demand of $50 \mathrm{kWh} \mathrm{m}^{-2}$ [19]. The average living space areas are taken from Timm [37] for different regions in Germany as follows: Berlin $40 \mathrm{~m}^{2}$, Munich $44 \mathrm{~m}^{2}$, Cologne $42 \mathrm{~m}^{2}$ and Karlsruhe $43 \mathrm{~m}^{2}$.

\section{RESULTS AND DISCUSSION}

\subsection{Spatial distribution of groundwater temperatures}

The interpolated GWT fields for each city are shown Fig. 2. They exhibit a common pattern in SUHIs with closed isotherms and generally maximum temperatures around the city centres. The observed SUHI intensities decrease towards suburban or rural areas, where anthropogenic affectation is less intense. In these areas, the shallow GWT ranges between $8^{\circ} \mathrm{C}$ and $11^{\circ} \mathrm{C}$ in the studied cities mirroring the annual mean SAT indicated in Table 1 . The 
relative large-scale thermal anomalies observed in the city downtowns are likely associated with long-term and extensive changes in land use. For the largest considered cities, the temperatures vary between $13^{\circ} \mathrm{C}-18^{\circ} \mathrm{C}$. In Karlsruhe, however, the highest GWT is observed in an industrial area (western part of the city) where important reinjections of thermal waste water are operated [38].

Another common feature in SUHIs is their spatial heterogeneity which is partially caused by the spatial density and depth of the temperature measurements. This is more evident in Munich where the dense network of observation wells allows to identify hot spots with temperature of up to $20^{\circ} \mathrm{C}$ nearby building cellars and at the same time, low temperatures close to the background values in green spaces in the inner-city [27]. This heterogeneity is also enhanced by the variety of heat sources within a typical urban area including subway systems, district heating networks, shallow geothermal systems, heat losses from basements in buildings and increased surface and air temperatures [1-2] and [38].

\subsection{The estimated theoretical geothermal potential}

With the parameters ranges listed in Table 2, the theoretical heat content $Q$ can be estimated for each city. The corresponding minimum, maximum and mean values are shown
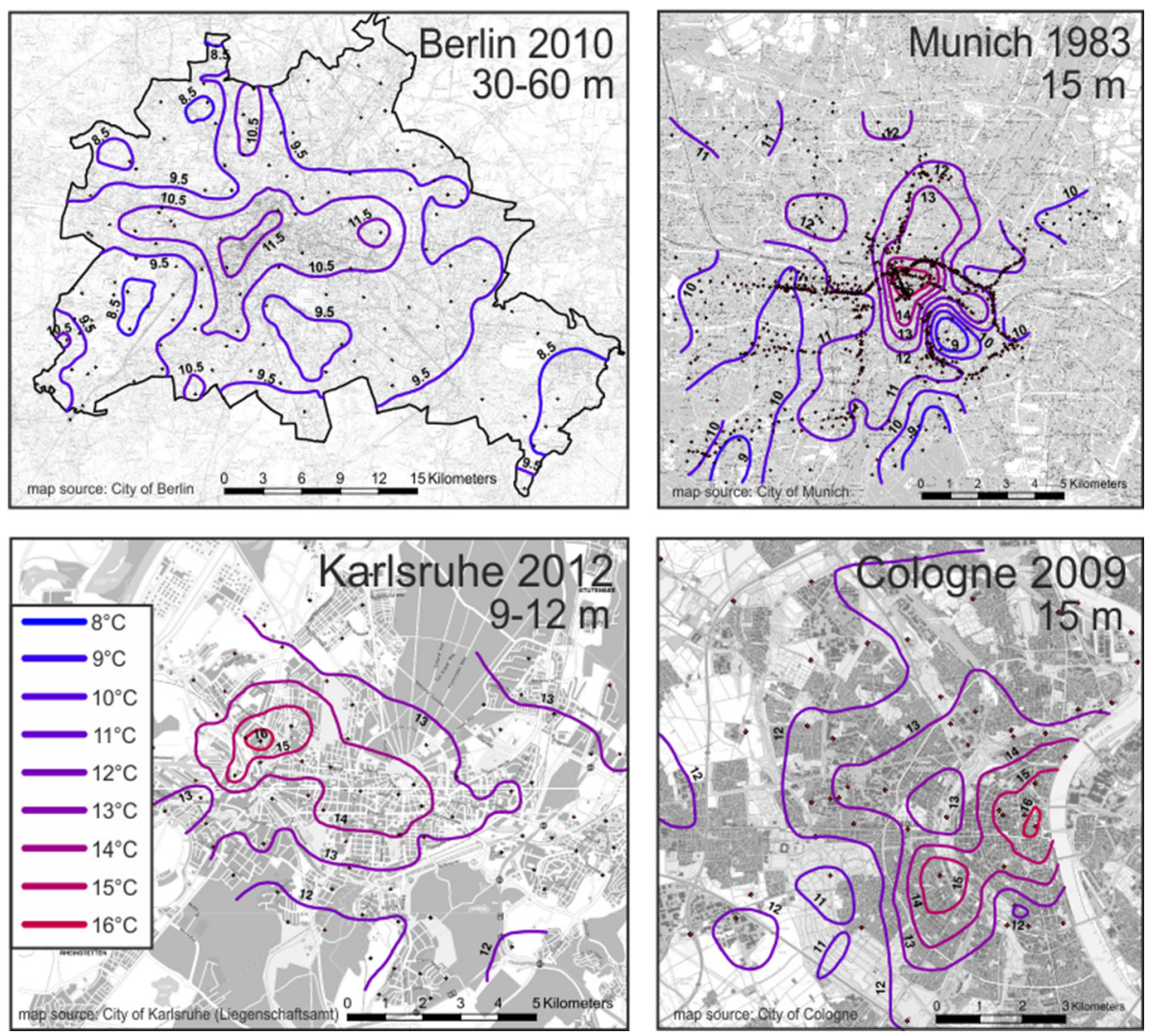

Figure 2: Isotherm maps of groundwater temperature under the studied cities. The dots represent the location of the observation wells [5]. 
Table 3: Geothermal potential of the studied cities.

\begin{tabular}{lccc}
\hline \multicolumn{5}{c}{$\begin{array}{c}\text { Potential underground } \\
\text { heat content } \\
{\left[\times 10^{12} \mathrm{~J} \mathrm{~km}^{-2}\right]} \\
\min -\max (\operatorname{mean})\end{array}$} & $\begin{array}{c}\text { Space-heating demand } \\
{\left[\times 10^{12} \mathrm{~J} \mathrm{~km}^{-2} \mathrm{year}^{-1}\right]}\end{array}$ & $\begin{array}{c}\text { Capacity for space-heating } \\
\text { [years] min }- \text { max (mean) }\end{array}$ \\
\hline Berlin & $155-874(440)$ & 27.8 & $5.6-31.4(15.8)$ \\
Munich & $26.7-350(112)$ & 20.5 & $1.3-17.1(5.5)$ \\
Cologne & $48.2-484(204)$ & 19.2 & $2.5-25.1(10.6)$ \\
Karlsruhe & $46.5-806(301)$ & 36.4 & $1.3-22.1(8.3)$ \\
\hline
\end{tabular}

in Table 3. Given the similarity in hydro-physical parameters and groundwater warming between the different cities, the estimated potential only varies within one order of magnitude. For comparison, Table 3 also includes the area-averaged space-heating demand. It is shown that the underground stored energy could cover this demand in the individual cities for at least 1.3-5.6 years while more optimistic estimations yield capacities of up to 17.1-31.4 years. These assessments can be judged as conservative since only the actual heat content in the urban aquifer is considered excluding the continuous power input from the associated anthropogenic sources. In fact, provided an appropriate exploitation technology, this continuous replenishment of thermal energy can supply part of the heating demand in a sustainable way. For the city of Karlsruhe for instance, by tapping only the annual anthropogenic heat loss, about $20 \%-30 \%$ of the annual space-heating demand could be covered sustainably [39]. However, these estimations of the geothermal potential are based on a lumped parameterization, which neglects the high variability of heat sources and subsurface hydrogeological conditions. These factors together with technological issues, will ultimately determine the site-specific heat gain from the urban aquifers.

\section{CONCLUSIONS}

The presented study cases exhibit the increased temperature in the shallow urban subsurface of several German cities. The thermal anomalies have a strong spatial heterogeneity with observed persistent values of up to $16^{\circ} \mathrm{C}$. Local temperatures however can reach up to $20^{\circ} \mathrm{C}$ near dominant heat sources yielding groundwater warming by more than $6 \mathrm{~K}$ in comparison to background conditions. Several anthropogenic sources such as heat losses from buildings and other infrastructure, direct geothermal use of aquifers and changes in land cover drive the long-term and multi-scale thermal alteration in the studied urban aquifers.

The accumulated heat content is substantial and urban aquifers can act as attractive and easily accessible reservoirs and also storage for thermal energy and waste heat. The presented estimation of the individual space-heating capacities reveals that the theoretical geothermal potential could fulfil the residential heating demand in all studied cities for at least several years, and assuming more optimistic values even for decades. Considering the permanent anthropogenic heat input from the urban structures into the shallow aquifer, the heating demand of the cities could also be partly satisfied for a longer period. However, to meet the requirements for such a sustainable underground management, a more detailed examination of the transient behaviour of these subsurface urban heat islands with geothermal usage is still needed. 


\section{ACKNOWLEDGEMENTS}

This work was supported by the Swiss National Science Foundation (SNSF) under grant number 200021L 144288, and the German Research Foundation (DFG), under grant number BL 1015/4-1. Special thanks are also given to Kathrin Menberg and Ke Zhu.

\section{REFERENCES}

[1] Ferguson, G. \& Woodbury, A.D., Subsurface heat flow in an urban environment. Journal of Geophysical Research: Solid Earth, 109(B2), 2014.

[2] Taylor, C.A. \& Stefan, H.G., Shallow groundwater temperature response to climate change and urbanization. Journal of Hydrology, 375(3), pp. 601-612, 2009. http://dx.doi.org/10.1016/j.jhydrol.2009.07.009

[3] Eggleston, J. \& McCoy, K.J., Assessing the magnitude and timing of anthropogenic warming of a shallow aquifer: example from Virginia Beach, USA. Hydrogeology Journal, 23, pp. 105-120, 2015. http://dx.doi.org/10.1007/s10040-014-1189-y

[4] Balke, K., Das Grundwasser als Energieträger. Brennstoff-Wärme-Kraft, 29, pp. 191194, 1977.

[5] Menberg, K., Bayer, P., Zosseder, K., Rumohr, S. \& Blum, P., Subsurface urban heat islands in German cities. Science of the Total Environment, 442, pp. 123-133, 2013. http://dx.doi.org/10.1016/j.scitotenv.2012.10.043

[6] Müller, N., Kuttler, W. \& Barlag, A.-B., Analysis of the subsurface urban heat island in Oberhausen, Germany. Climate Research, 58(3), pp. 247-256, 2014. http://dx.doi.org/10.3354/cr01195

[7] García-Gil, A., Vazquez-Sune, E., Garrido Schneider, E., Angel Sanchez-Navarro, J. \& Mateo-Lazaro, J., The thermal consequences of river-level variations in an urban groundwater body highly affected by groundwater heat pumps. Science of The Total Environment, 485-486, pp. 575-587, 2014.

http://dx.doi.org/10.1016/j.scitotenv.2014.03.123

[8] Epting, J. \& Huggenberger, P., Unraveling the heat island effect observed in urban groundwater bodies - Definition of a potential natural state. Journal of Hydrology, 501, pp. 193-204, 2013. http://dx.doi.org/10.1016/j.jhydrol.2013.08.002

[9] Taniguchi, M., Shimada, J., Tanaka, T., Kayane, I, Sakura, Y., Shimano, Y., DapaahSiakwan, S. \& Kawashima, S., Disturbances of temperature depth profiles due to surface climate change and subsurface water flow: 1 . An effect of linear increase in surface temperature caused by global warming and urbanization in the Tokyo Metropolitan Area, Japan. Water Resources Research, 35(5), pp. 1507-1517, 1999. http://dx.doi.org/10.1029/1999WR900009

[10] Yamano, M., Evolution of the Subsurface Thermal Environment in Urban Areas: Studies in Large Cities in East Asia, in Groundwater and Subsurface Environments, Springer, pp. 201-230, 2011. http://dx.doi.org/10.1007/978-4-431-53904-9_11

[11] Liu, C., Shi B., Tang, C. \& Gao, L., A numerical and field Investigation of underground temperatures under urban heat island. Building and Environment, 46(5), pp. 1205-1210, 2011. http://dx.doi.org/10.1016/j.buildenv.2010.12.015 
[12] Zhan, W., Ju, W., Hai, S., Ferguson, G., Quan, J., Tang, C., Guo, Z. \& Kong, F., Satellite-derived subsurface urban heat island. Environmental Science \& Technology, 48, pp. 12134-12140, 2014. http://dx.doi.org/10.1021/es5021185

[13] Hötzl, H. \& Makurat, A., Veränderungen der Grundwassertemperaturen unter dicht bebauten Flächen am Beispiel der Stadt Karlsruhe. Zeitschrift der Deutschen Geologischen Gesellschaft, 132, pp. 767-777, 1981.

[14] Bonte, M., Stuyfzand, P.J., Hulsmann, A. \& Van Beelen, P., Underground thermal energy storage: environmental risks and policy developments in the Netherlands and European Union. Ecology and Society, 16(1), p. 22, 2011.

[15] Brielmann, H., Griebler, C., Schmidt, SI., Michel, R. \& Lueders, T., Effects of thermal energy discharge on shallow groundwater ecosystems. FEMS Microbiology Ecology, 68(3), pp. 273-286, 2009.

http://dx.doi.org/10.1111/j.1574-6941.2009.00674.x

[16] Allen, A., Milenic, D. \& Sikora, P., Shallow gravel aquifers and the urban 'heat island'effect: a source of low enthalpy geothermal energy. Geothermics, 32(4), pp. 569-578, 2003.

http://dx.doi.org/10.1016/S0375-6505(03)00063-4

[17] Arola, T. \& Korkka-Niemi, K.,The effect of urban heat islands on geothermal potential: examples from Quaternary aquifers in Finland. Hydrogeology Journal, 22, pp. 1-15, 2014.

http://dx.doi.org/10.1007/s10040-014-1174-5

[18] Sinnathamby, G., Gustavsson, H., Korkiala-Tanttu, L. \& Perez Cervera, C., Numerical analysis of seasonal heat storage systems of alternative geothermal energy pile foundations. Journal of Energy Engineering, 141, 2014.

[19] Zhu, K., Blum, P., Ferguson, G., Balke, K.D. \& Bayer, P., The geothermal potential of urban heat islands. Environmental Research Letters, 6, 2011. http://dx.doi.org/10.1088/1748-9326/6/1/019501

[20] Zhang, Y., Soga, K. \& Choudhary, R., Shallow geothermal energy application with GSHPs at city scale: study on the city of Westminster. Géotechnique Letters, 4, pp. 125-131, 2014.

http://dx.doi.org/10.1680/geolett.13.00061

[21] Hähnlein, S., Bayer, P., Ferguson, G. \& Blum, P., Sustainability and policy for the thermal use of shallow geothermal energy. Energy Policy, 59, pp. 914-925, 2013. http://dx.doi.org/10.1016/j.enpol.2013.04.040

[22] Vienken, T., Schelenz, S., Rink, K. \& Dietrich, P.,Sustainable intensive thermal use of the shallow subsurface-a critical view on the status quo. Groundwater, 53, pp. 356-361, 2014, doi: 10.1111/gwat.12206. http://dx.doi.org/10.1111/gwat.12206

[23] Banks, D., An Introduction to Thermogeology: Ground Source Heating and Cooling, John Wiley \& Sons: Oxford, 2012. http://dx.doi.org/10.1002/9781118447512

[24] Rybach, L. \& Eugster, W.J., Sustainability aspects of geothermal heat pump operation, with experience from Switzerland. Geothermics, 39(4), pp. 365-369, 2010. http://dx.doi.org/10.1016/j.geothermics.2010.08.002 
[25] Rivera, J.A., Blum, P. \& Bayer, P., Ground energy balance for borehole heat exchangers: Vertical fluxes, groundwater and storage. Renewable Energy, 83, pp. 1341-1351, 2015. http://dx.doi.org/10.1016/j.renene.2015.05.051

[26] Henning, A. \& Limberg, A., Veränderung des oberflächennahen Temperaturfeldes von Berlin durch Klimawandel und Urbanisierung. Brandenburgische Geowiss. Beitr, 19(1), pp. 81-92, 2012.

[27] Dohr, F., Die Grundwassertemperatur im oberflächennahen Grundwasser des Stadtgebietes München (PhD thesis), Ludwig-Maximilians-Universität: Munich, 1989.

[28] Hannappel, S. \& Limberg, A., Ermittlung des Flurabstandes des oberflächennahen Grundwassers in Berlin (Determination of the floor distance of shallow groundwater in Berlin). Brandenburg Geowiss Beitr, 14, pp. 65-74, 2007.

[29] Seiler, K., Durchlässigkeit und Porosität von Lockergesteinen in Oberbayern. Mitteilung zur Ing.-u. Hydogeologie, 9, pp. 105-126, 1979.

[30] Zosseder, K., Heterogenitäten bei PAK-Kontaminationen im Grundwasser. Bochumer Geowiss. Arb, 12, p. 236, 2007.

[31] Geyer, O.F. \& Gwinner, M.P., Geologie von Baden-Württemberg, 5 edn., Stuttgart: Schweizerbart, 2011.

[32] VDI., Thermische Nutzung des Untergrundes (Guideline for thermal use of the underground). In VDI-Richtlinie 4640, Verein Deutscher Ingenieure (VDI)-Gesellschaft Energietechnik: Germany, 2012.

[33] Limberg, A. \& Thierbach, J., Hydrostratigraphie in Berlin - Korrelation mit dem Norddeutschen Gliederungsschema. Brandenburgische Geowissenschaftliche Beiträge, 9, pp. 65-68, 2002.

[34] Kerl, M., Runge, N., Tauchmann, H. \& Goldscheider, N., Hydrogeologisches Konzeptmodell von München: Grundlage für die thermische Grundwassernutzung. Grundwasser, 17(3), pp. 127-135, 2012. http://dx.doi.org/10.1007/s00767-012-0199-8

[35] Schafer, W., Wickert, F. \& Tiehm, A., Modellrechnungen zur Quantifizierung von NA-Prozessen fur den LCKW-Schadensfall in Karlsruhe-Ost/Killisfeld. Grundwasser, 12(2), pp. 108-124, 2007.

[36] Prinz, H. \& Strauss, R., Abriss der Ingenieurgeologie,Elsevier Spektrum akademischer Verlag: München, p. 671, 2006.

[37] Timm, U., Wohnsituation in Deutschland 2006 - Ergebnisse der Mikrozensus-Zusatzerhebung, in Wirtschaft und Statistik, Statistisches Bundesamt: Wiesbaden, 2008.

[38] Menberg, K., Blum, P., Schaffitel, A. \& Bayer, P., Long-term evolution of anthropogenic heat fluxes into a subsurface urban heat island. Environmental Science \& Technology, 47(17), pp. 9747-9755, 2013.

http://dx.doi.org/10.1021/es401546u

[39] Benz, S.A., Bayer, P., Menberg, K., Jung, S. \& Blum, P., Spatial resolution of anthropogenic heat fluxes into urban aquifers. Science of The Total Environment, 524-525, pp. 427-439, 2015.

http://dx.doi.org/10.1016/j.scitotenv.2015.04.003 